\title{
A Critical Assessment of an Extended Learning Environment in Interior Design Studio
}

\author{
Zeynep Ceylanli \\ Ozyegin University, Faculty of Architecture and Design, Istanbul, Turkey \\ Elif Aktas Yanas \\ Ozyegin University, Faculty of Architecture and Design, Istanbul, Turkey
}

Received: May 17th 2021, Revised: June 20th 2021, Accepted: June 22nd 2021.

Refer: Ceylanli, Z., Aktas Yanas, E., (2021), A Critical Assessment of an Extended Learning Environment in Interior Design Studio, Journal of Design Studio, V.3, N.1, pp 71-81,

Z. Ceylanli ORCID: 0000-0002-0564-3596, E. Aktas Yanas ORCID: 0000-0002-4477-9795

DOI: $10.46474 /$ jds. 938258 https://doi.org/10.46474/jds.938258

\begin{abstract}
This paper presents a critical assessment of an interior design studio that was constructed face-to-face then online as an extended studio environment through spatial and technological means. In the Interior Design Studio III, students were expected to design an experiential retail store aiming at answering the contemporary customer and brand interactive experience. The concept of 'interactive experience' was central not only in terms of a project outcome but also of the studio process: an experiential learning environment is designed to enhance the understanding of the design studio. Within this scope, the collaboration with the maker lab of the university provided technological interfaces and analog model making methods while also expanding the limits of studio space. The interactive experience would not only result in the project outcome but also be integrated to the studio model. This studio model and the topic was conducted face-to-face in the campus three semesters consecutively, while the following two were held online. The study is based on exploratory research using qualitative techniques to analyze the design process of the students in the face-to-face and online experiential learning environment. The main objective is to overview and assess the interior design studio by providing a new perspective to the students about space and user relationship regarding interaction and atmosphere not only in terms of the given design problem but also the 'environment' they are experiencing the ways of design.
\end{abstract}

Keywords: Interior design studio, Interactive experience, Experiential retail design, Extended learning environment

\section{Introduction}

Interior design is not only a physical medium that solves spatial problems in a functional, aesthetic, technical and creative way but also it is an interactive mechanism that constructs the user's relationship with the space. The interaction between humans and the built environment has always been an essential factor that shapes the architectural space creation process. Architectural space is experienced not only intellectually but also emotionally and sensually with the whole physical body. As Mallgrave points out "architecture is at heart a more deeply embodied phenomenon than the merely visual; it deals with many more sensory and subliminal dimensions (spatial, material, and emotional)" (Mallgrave, 2010, p.159). In architecture and interior design education, although students are encouraged to perceive the multi-sensorial qualities of the space that are appealing to the skin, ear, nose, body and skeleton (Pallasma, 2014), the experiential space experience often falls short of reflecting on the studio outputs. Considering that visionbased representations are dominant over other sensory modalities in architectural design 


\section{Journal of \\ Design Studio}

v:3 n:1 July 2021

practice, it can be understood that creating designs that appeal to other senses in addition to visual perceptions is a challenging process for interior design students. In a study which included interviews with various practitioners, even experienced architects have been found to neglect the body in their design practice rather than the anthropometric properties (Imrie, 2003). Same study reveals that in architectural design education, the body gains little attention as well. However, in order to create a functionally and aesthetically integrated spatial experience, interaction of the body with the built environment should be considered in a holistic approach, where experience is embodied in a multi-dimensional level.

In this study, in order to extend the students' understanding of multi-sensory perception of space and encourage them to design embodied experiences in their studio projects, it is aimed to create an experiential learning environment in the interior design studio. To extend the traditional studio model, which is based on hands-on learning in a physical studio environment, the proposed studio program is constructed around several precedents for students to practice a more intrinsic learning model. The data of the assessment consists of students' weekly submissions on LMS (including juries and presentations) and the field notes (discussions, jury critiques, instructors' observations). This data is then analyzed based on the literature review on retail design, interactive spatial experience, design studio and the expected outcomes of the proposed studio program, assessing the face-toface and online studio experiences. It is crucial to note that these outcomes are separated from the main learning outcomes of the INAR301 studio in the curriculum. The proposed studio program offers a new means of understanding the studio environment enhanced by the collaboration of the maker lab, which eventually would provide a different perspective towards the spatial design problem, and consequently would enrich the very spatial experience itself and be reflected in the outcomes of the studio course. This paper looks at the means and limitations of this extended studio model in the changing mediums.

\section{Literature Review Experiential design and retail design}

As mentioned above, the interactive spatial experience is located at the center for the case of the interior design studio, in order to extend the students' perception of space in a multimodal, embodied, enactive way. Interactive experience occurs as a result of the interactive dialog between our perceptual capacities, embodied being, and the affordance of the environment (Yakhef, 2015). In this context, design problems that are assigned to students are constructed in such a way that they would examine both the pure relationship that the body establishes with the space and the ways to enrich this interaction through the use of analog or digital interfaces. With regards, students first work on brand representation in the context of space-place, where they create a spatial experience of the brand identity using only physical means and then on experiential retail store in the process that consists of two phases. In this first phase, it is aimed at students to make practice of transforming conceptual knowledge of the brand identity to an embodied physical experience before moving to the design of the actual retail store. Given that design is a dynamic process of adapting and transforming prior experience knowledge (Oxman, 1990), this first phase was planned to accommodate as a design precedent for the students. In this phase, students concentrated on only the abstraction of brand identity and its physical manifestation as a spatial experience during the first six weeks. Thus, providing the basis for exploiting the conceptual knowledge of precedents as Akın (2002) suggested, where conceptual abstractions derived from it bridge between the conceptual and the physical (Akın, 2002; Oxman, 2004). Other precedents were also introduced during the semester to help them to turn the knowledge into abstract modes and apply them to their retail store project, which are shown in Table 1. The concept of interactive spatial experience is extended into a new realm in the second phase of the studio, where students were introduced to the concept of 'experiential retail store'.

Experiential retail store is derived from the retail understanding where brands market the 


\section{Journal of \\ Design Studio}

v:3 n:1 July 2021

\begin{abstract}
"experience" created by the product than the product itself. The rapidly changing consumption patterns in the last two decades have led the retailing industry to keep pace with this process and to conduct sectoral and academic studies on the development of the concept of customer experience. The studies on customer experience modules by Schmitt (1999; 2003; 2010), Brakus et al. (2009), and Verhoef et al. (2009) provide the theoretical framework in the literature. According to Schmitt (1999), experiential marketing differs from traditional marketing that it considers customers' sensory and emotional experiences rather than treating them as rational decision makers who only consider functional features of shopping activities.
\end{abstract}

In this context, Schmitt (1999) suggests five different experience modules that should be managed in experiential marketing; sensory experiences (SENSE), emotional experiences (FEEL), creative cognitive experiences (THINK), physical experiences, behaviors and lifestyles (ACT), and experiences arising from social-identity and culture (RELATE). Similarly, Verhoef et al. (2009) discusses the customer experience with a holistic perspective that includes the customer's cognitive, affective, emotional, social and physical responses that the customer establishes with the retailer. In particular, the fact that shopping via the internet accessible from anywhere at any time of the day increases the importance of instore sensory and interactive experience. Servais et al. (2019) define the characteristics of the experiential retail space as focusing on the customer experience, establishing a strong relationship with brand identity, providing customers with more than the in-store "selling products" function and often providing an "unexpected", original experience. Moreover, studies in the literature show that the customer's experience in the store has a significant impact on retail sales. According to Bagdare and Jain (2013), contemporary retail is shaped by "experience stores" that increase customer satisfaction and brand loyalty by providing a pleasant shopping experience. As the importance of atmospheres that elicit positive emotions in customers grows in retail sales, the role of in-store interactive experiences, socializing, and communication areas in space organization grows. Correspondingly, retail design is now recognized as a distinct transdisciplinary design discipline concerned with the creation of virtual and physical spaces in which to sell products and services to customers (Quartier, Claes and Vanrie, 2019). At this point, the role of the interior architect/designer in the design of the retail store is to enhance the "customer experience" by creating an atmosphere that is integrated with the brand by considering the different aspects of the customer experience. In this context, it goes beyond the sensory and physical properties of the atmosphere such as light, sound, color tones, temperature, material texture, as in Pallasmaa's $(2014$, p.21) definition, atmosphere is "an experiential property or characteristic that is suspended between the object and the subject".

In interactive spatial design, the flow of interaction and the spatial design supported by technology should be considered from the conceptual design stage, in addition to the relationship between physical space and human experiences (Ciolfi, 2004). The enhanced instore experience has the potential to strengthen the retailing industry, which must compete with online sales. Thereby, it is important for retailers to invest in technological advancements that will provide experiences that elicit positive emotions, thereby increasing consumer curiosity and imagination (CacheroMartínez ve Vázquez-Casielles, 2017). Helmefalk's (2019) research shows that multisensory experiences in stores increase sales rates by 3.5 times when compared to traditional stores and also contribute to sales rates by increasing browsing time. Designers, on the other hand, will be the most important actors in this interdisciplinary process, embracing the potentials of existing technologies such as rapid prototyping tools like Ardunio and exploring the limits of interactive design with engineers (Hornecker, 2011). The changing retail means and habits have been interpreted in the interior design studio regarding this transformation, and the process and results have been analyzed and revealed through this study. 


\section{Journal of \\ Design Studio}

v:3 n:1 July 2021

\section{Extended means of design studio}

Design studio offers a collaborative learning and experimenting environment, where the designers practice a "multimodal, multisensory, ubiquitous" communication that addresses the designers' to "artistic, emotional and experiential ... thinking" and "instrumental and practical reasoning." (Vjas, Veer, and Nijholt, 2013, p. 415-16). Design studio has long been the subject of alteration via experimentation of digital platforms (Ioannou, 2018); this way of 'blended learning' did not provide a complete online design studio experience (Fleischmann 2019) but highlighted the necessary steps to take in order to enhance it (Scupelli, Candy and Brooks, 2019).

One of the ways of elevating the physical studio experience is to prolong the design practicing environment. Referred as an extension the Doit-Yourself culture soaked in technology, a collaboration with a maker lab could not only facilitate the enhanced physical modelling of the designed spaces and the "communities of practice', but also would reveal the potentials of "hands-on, design-build education to stimulate innovation, creativity, and entrepreneurship" (Forest et al., 2014, p. 2). Maker labs in their own spaces provide tools (software and hardware) and materials for students to "express their creativity' and work and produce together (Hynes and Hynes 2018).

The learning environment of the students has already extended to digital mediums, not only the social media platforms but also digital libraries support this shift. Masdeu and Fuses (2017, p. 14) give an example of distance and blended learning on an international collaboration of virtual design studio, asserting that a mixture of conventional studio practices and distance learning "results in a multiplicity of techniques that enrich and facilitate students' learning in the studio".

\section{Studio model as an experiential learning environment \\ Description of the studio model \\ The Interior Design Studio III (INAR301) was configured in the Fall 2018 semester as a two- phase design problem on retail design, and has}

been consecutively conducted for five semesters (Table 1). INAR301 is the third interior design studio among six in the curriculum of the Interior Architecture and Environmental Design Program, where in their first year students take Design and Architectural Design Studio I in conjunction with the Architecture Program. Theoretically, the students begin the studio with basic structural and computational design courses fulfilled, and compulsorily completed their first two interior design studios. In INAR301, the first problem they deal with is temporary structures via experimenting with materiality and place making: they are asked to design a temporary pavilion in a limited volume for a product-based company they choose without revealing the brand's name or displaying the products, which requires a thorough research on brand identity (Figure 1). This phase is planned to be the precedent of the second phase where the students are required to design a two-story retail store in an open-air marketplace except for the last semester (Fall 2020) that they were given a semi-open shopping mall to work in (Figure 2).

In order to adapt to the changing retail means and habits, the studio program requires the students to think, investigate and interpret the customer experience, their perception of the brand and the relation between brand and its identity. In the two-phase process, the students firstly work on the brand representation in terms of context-space, then switch to interactive spatial experience. The main nodes of the program are temporary space, brand representation, sensory and interactive spatial experience, tools and interfaces used during the process of design.

The studio program contains a long-term collaboration with the maker laboratory of the university (OpenFab) in which an industrial designer and an electronics engineer offered lectures, workshops, Q\&A sessions, and feedback in the juries regarding the feasibility of the suggested interaction methods and available tools and interfaces for their production. Through this collaboration the design studio experience was to extend, new means of thinking and doing were to be 


\section{Journal of \\ Design Studio}

v:3 n:1 July 2021

Table 1: Studio model formation process
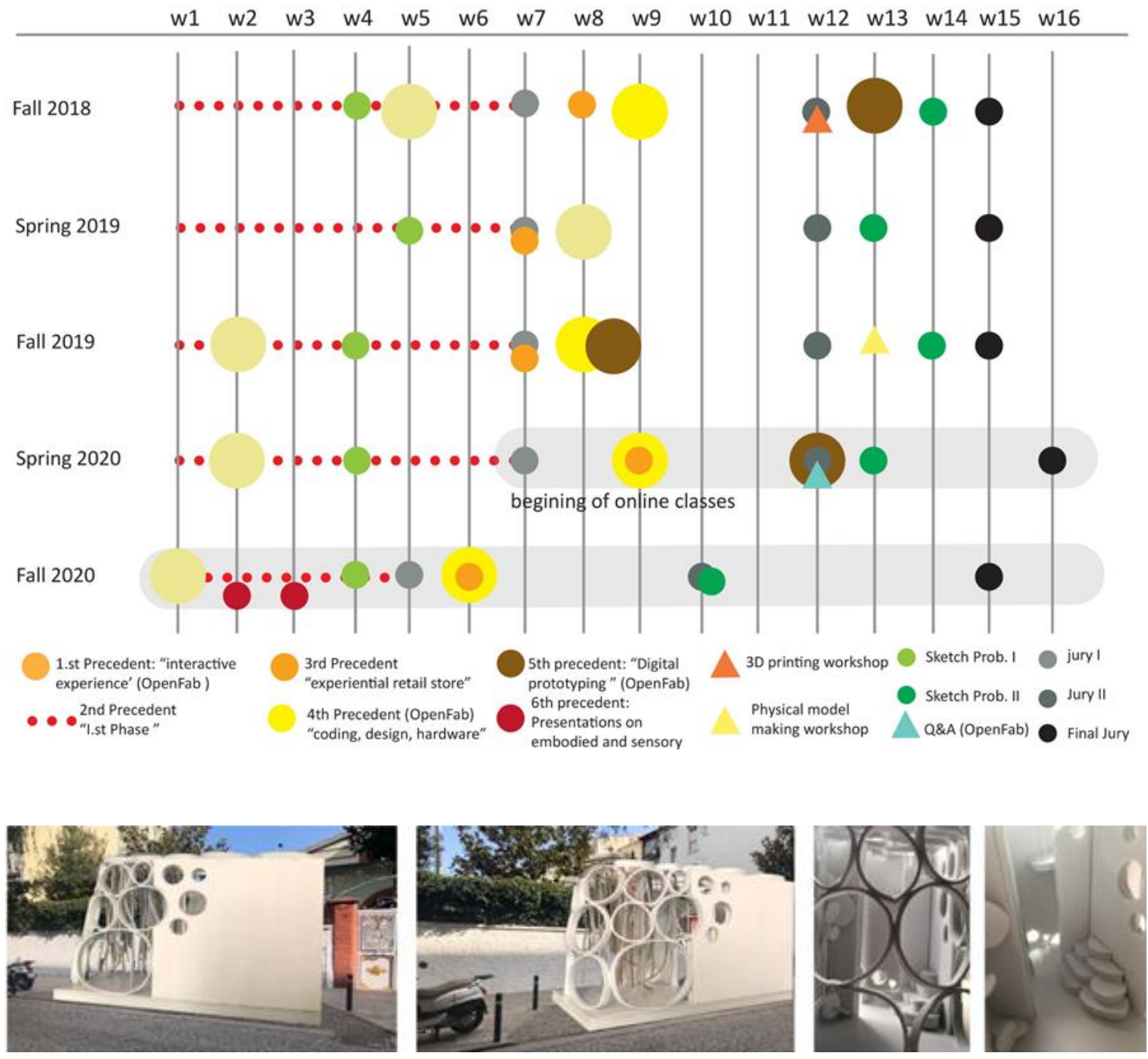

Figure 1: Example from the first phase, photomontage of the temporary pavilion into the actual site. (S23)

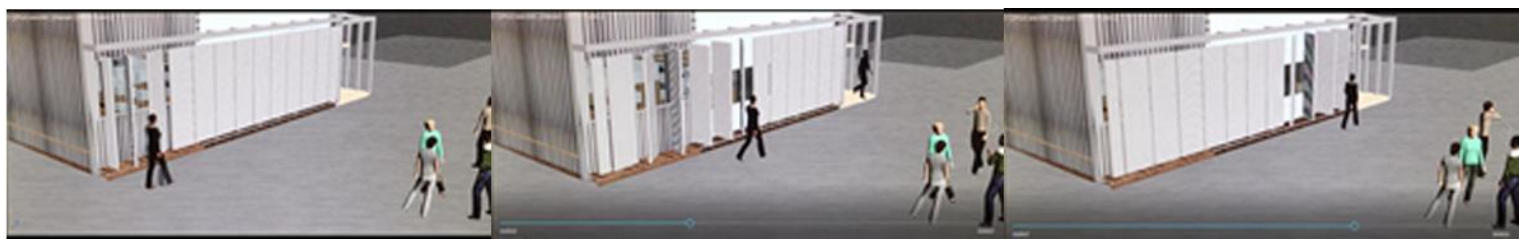

Figure 2: Example from the second phase, animated video of the interactive experience. (S40)

experimented, and technological tools and interfaces were to be explored. Since the given design problem is on spatial experience, it is considered important for the students to be able to use all the sensory means during the design process. 


\section{Journal of \\ Design Studio}

v:3 n:1 July 2021

\section{Studio environment}

The pilot program was introduced in Fall 2018 semester with a thorough evaluation at the end in terms of the outcomes, scheduling, and the collaboration with the maker lab (Ceylanl1 and Aktaş Yanaş 2019). The physical spaces that the program took place were the semiweekly interior design studio (five hours at a time) and the maker laboratory. In the studio, design briefs, critique sessions, student presentations, sketch exams, and juries took place (Figure 3). Whereas in the OpenFab, the lectures on interactive experience, coding, design and hardware in addition to the workshop on Arduino prototyping were provided. Table 1 presents how each precedent and studio/maker lab activity fall on the semesterly schedule.
The following semester, the program of the studio had deficiencies due to the scheduling problems with the OpenFab: the first meeting that involves introduction of the concept of 'interactive experience' moved further to the eight week after the first jury and the introduction of the 'experiential retail store' followed by student presentations. In addition, the Arduino workshop which was originally planned during the studio hours could only occur after the studio as a workshop open to all students in the university. The participation of the interior design students was lower than expected.

The third semester, Fall 2019, occurred as planned from the beginning: the concept of interactive experience was introduced in the second week of the semester so that the students
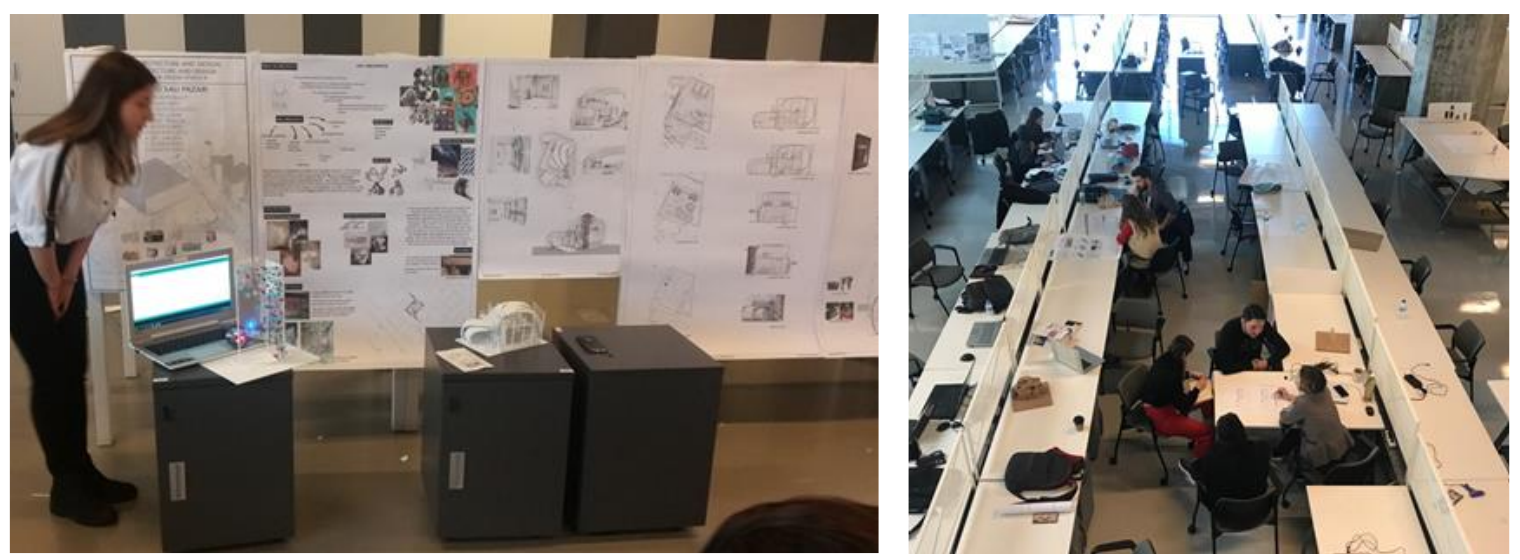

Figure 3: a) Jury and b) critique sessions in the studio. (Photos by Z. Ceylanl and M. Şahin)
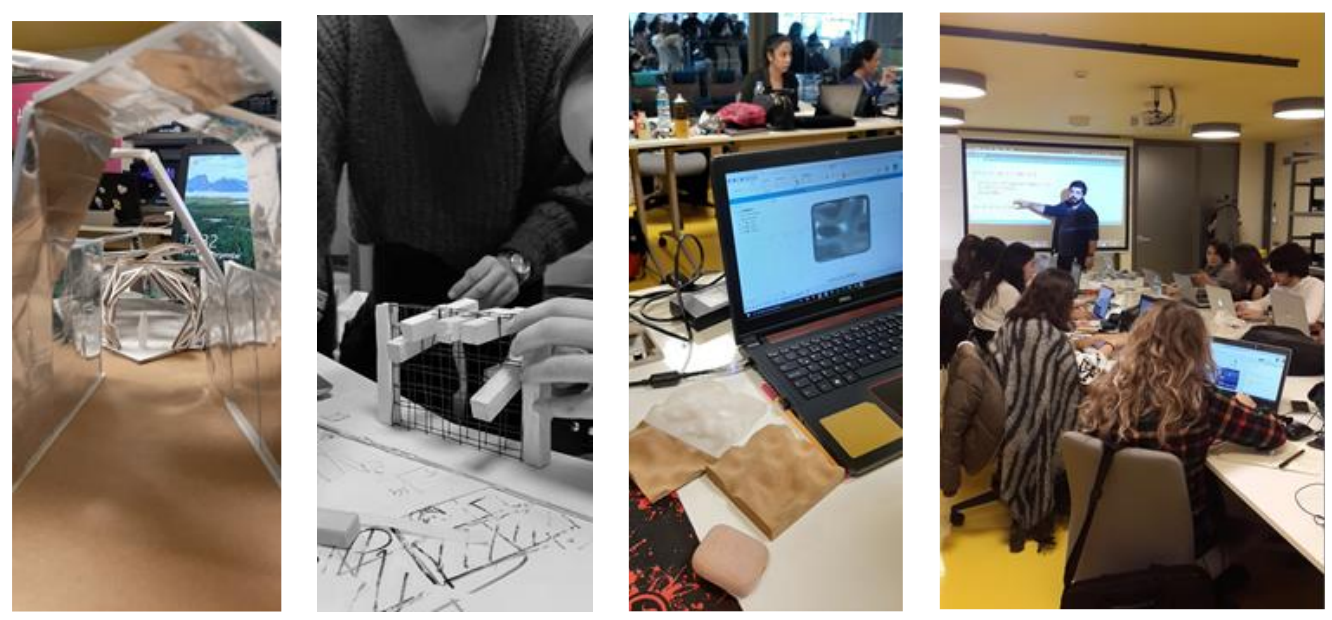

Figure 4: $a, b, c)$ Model making and d) Arduino workshops in the maker lab. (Photos by G. Coşkun) 


\section{Journal of \\ Design Studio \\ v:3 n:1 July 2021}

began to incorporate the very idea into their design project from the beginning. Furthermore, OpenFab offered a model making workshop towards the end of the semester prior to the final jury in order to materialize the spatial and interactive configuration that the students had been working on in their designs (Figure 4). The Spring 2020 semester also began with the same programming until just before the first jury, when the university announced the remote conduct of the classes at the end of the fifth week.

After a week of recess, the studio moved to online platforms resuming from the sixth week, and thus, the first jury. The syllabus was adapted according to the new online situation: Microsoft Teams was introduced by the university which replaced the studio environment, the official learning management system of the university (LMS) was used more extensively for the online critique sessions and remote feedbacks -which enables annotated drawing, writing, audio and video recording. OpenFab offered an extra Q\&A session during the studio since the physical model making workshop could not actualize. This, in fact, was not only due to the impracticability of the use of physical means in the maker lab, but also due to the pandemic situation where the students had difficulties accessing the model making or prototyping equipment. Still, the students received the pre-recorded lectures and tutorials of the OpenFab, and were encouraged to use any material they had at home to produce a palpable model of their design.
The obligatory and inescapable experience of the online studio education generated several changes in the topic and the site of the project area in the Fall 2020 semester. The given semiopen shopping mall was in another city and the contextual framework was based upon the significance of the area in the ancient literature. The two-phase program structure did not change. The collaboration of the OpenFab continued as planned. However, additional lectures on multi-sensory experience and bodyspace relation were inserted therein. The virtual replica of the studio space was Zoom this time, which did not provide the 'classroom' interface as Microsoft Teams did (Figure 5a). As an additional virtual platform of sharing and annotating, Miro was offered to the students where they could present their research and see other's sketches, concept boards, model images, and the annotations of the studio instructors and their peers. Additionally, OpenFab produced an apparatus for the laptops that enables the students and the instructors to synchronously screen their sketching during the online critiques (Figure 5b). Although still the physicality of the maker lab was unavailable, the students kept their correspondence with the OpenFab and sought for further feedback to solve their interactive design problem.

\section{Discussion}

The outcomes of the INAR301 studio are twofold: the technical and representational requirements constitute one part, embodied and interactive spatial experience constitute the other (Vjas, Veer, and Nijholt, 2013). In this paper the focus is on the latter. The comparative assessment of the extended studio model is
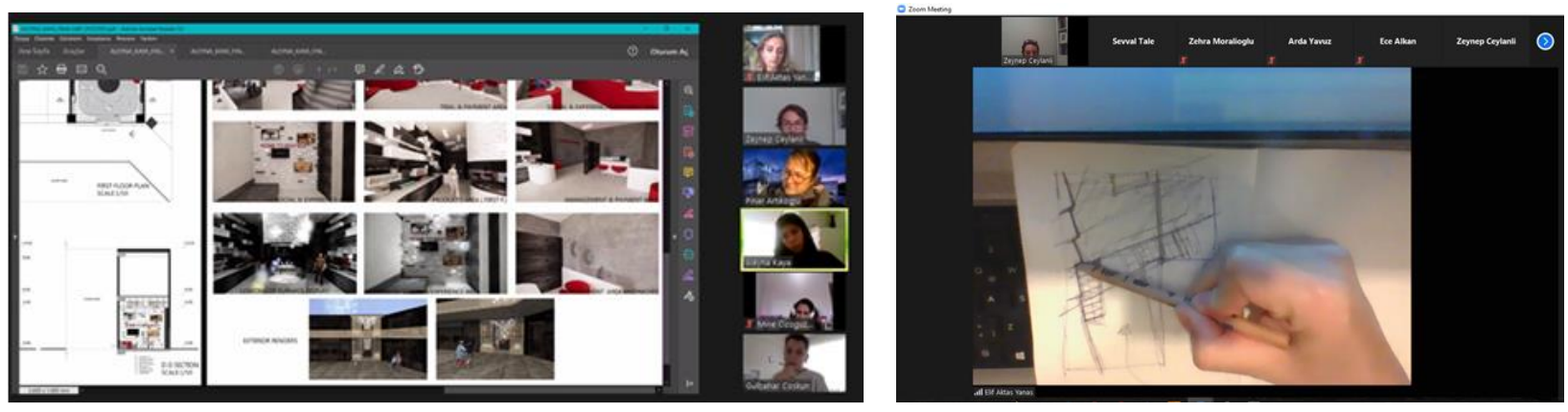

Figure 5: a) Jury and b) critique sessions in the virtual studio. (Photos by Z. Ceylanll)

Journal of Design Studio, v:3 n:1

Ceylanli, Z., Aktas Yanas, E., (2021), A Critical Assessment of an Extended Learning Environment in Interior Design Studio. 


\section{Journal of \\ Design Studio}

v:3 n:1 July 2021

conducted according to four essential criteria based on the literature regarding the experiential retail design: embodied experience, brand identity, interactive experience, and holistic approach were sought in the students' projects (Table 2). In reference to Schmitt's (1999) experience modules, the first criterion 'embodied experience created towards design problem' seeks for the means of sensory and/or emotional experiences; whereas the second criterion 'reflection of brand identity to design and interactive experience' includes the experiences related to social-identity and culture in addition to the sensory and the emotional. The third criterion "enhancement of interactive experience with technological and/or analogous tools' pertains to creative cognitive experiences, physical experiences, behaviors and lifestyles and is a pivotal point of the study that shows the contribution of the precedents provided by the collaboration with the OpenFab. Finally, the fourth criterion 'holistic approach towards interactive experience and spatial integration' reveals the level of including the physical and the identityculture related experiences.

The number of the students per semester vary from min.10 (Fall 2018) to max.18 (Fall 2020), which makes up 61 in total. Some of these students took the studio course for more than one semester. Table 1 summarizes the weekly program applied per semester and clearly puts forth the additional and lacking precedents offered throughout the face-to-face and online studio.

Table 2 shows the students who achieved the assessment criteria (AC) of the program according to the semesters that the program was conducted. In Fall 2018, the program started in the university campus, framing the learning environment within the studio and the maker lab. While 3 out of 10 students succeeded in $\mathrm{AC} 1$ and $\mathrm{AC} 4$ that semester, the $\mathrm{AC} 2$ and $\mathrm{AC} 3$ doubled this rate, and 1 student managed to accomplish all four criteria. In Spring 2019, the majority of the students succeeded in $\mathrm{AC} 1$ and $\mathrm{AC} 2$, but the numbers dropped in $\mathrm{AC} 3$ and

Table 2: Comparative assessment of student (S\#) projects. The bold S\# indicates the student that appeared in all four criteria.

\begin{tabular}{|c|c|c|c|c|c|c|}
\hline & $\begin{array}{l}\text { Total number of } \\
\text { students in the studio: }\end{array}$ & 10 & 12 & 14 & 11 & 18 \\
\hline \# & Assessment criteria: & Fall 2018 & $\begin{array}{l}\text { Spring } \\
2019\end{array}$ & Fall 2019 & $\begin{array}{l}\text { Spring } \\
2020\end{array}$ & Fall 2020 \\
\hline 1 & $\begin{array}{l}\text { embodied experience } \\
\text { created towards design } \\
\text { problem }\end{array}$ & S3, S5, S6 & $\begin{array}{l}\text { S11, S12, } \\
S 14, S 17, \\
\text { S20, S21, } \\
S 22\end{array}$ & $\begin{array}{l}\boldsymbol{S} 23, \boldsymbol{S} 25, \\
S 27, S 28, \\
S 30, \boldsymbol{S 3 1} \\
S 33, S 33\end{array}$ & $\begin{array}{l}\text { S40, S43, } \\
S 44, S 32\end{array}$ & $\begin{array}{l}\text { S46, S47, } \\
\text { S50, S54, } \\
\text { S56, S58, } \\
S 59, S 60\end{array}$ \\
\hline 2 & $\begin{array}{l}\text { reflection of brand } \\
\text { identity to design and } \\
\text { interactive experience }\end{array}$ & $\begin{array}{l}\text { S3, S1, S5 } \\
\text { S6, S7, S10 }\end{array}$ & $\begin{array}{l}\text { S11, S12, } \\
\text { S13, S14, } \\
\text { S16, S17, } \\
\text { S19, S20, } \\
\text { S21 }\end{array}$ & $\begin{array}{l}S 23, S 25 \\
S 31\end{array}$ & $\begin{array}{l}S 39, \text { S40, } \\
S 41,\end{array}$ & $S 46, S 50$ \\
\hline 3 & $\begin{array}{l}\text { enhancement of } \\
\text { interactive experience } \\
\text { with technological } \\
\text { and/or analogous tools }\end{array}$ & $\begin{array}{l}S 1, S 2, S 3 \\
S 4, S 8, S 9 \\
S 10\end{array}$ & $\begin{array}{l}\text { S11, S14, } \\
\text { S16, S19, } \\
\text { S20 }\end{array}$ & $\begin{array}{l}\boldsymbol{S} 23, \boldsymbol{S} 25 \\
S 27, S 28 \\
S 30, \boldsymbol{S} 31 \\
S 35, S 37\end{array}$ & $\begin{array}{l}\text { S40, S44, } \\
S 32\end{array}$ & $\begin{array}{l}\text { S46, S47, } \\
\text { S50, S61 }\end{array}$ \\
\hline 4 & $\begin{array}{l}\text { holistic approach } \\
\text { towards interactive } \\
\text { experience and spatial } \\
\text { integration }\end{array}$ & $S 2, \mathbf{S 3}, S 7$ & $\begin{array}{l}\text { S11, S14, } \\
\text { S20 }\end{array}$ & $\begin{array}{l}S 23, S 25 \\
S 31\end{array}$ & $S 40$ & $\begin{array}{l}\text { S46, S47, } \\
\text { S50 }\end{array}$ \\
\hline
\end{tabular}




\section{Journal of \\ Design Studio}

v:3 n:1 July 2021

AC4. Yet, 2 students covered the four criteria. In Fall 2019, although 8 out of 14 students demonstrated $\mathrm{AC} 1$ and $\mathrm{AC} 3$ in their projects, AC2 remained significantly low. The number of students fulfilling all the criteria appears as 3. The Spring 2020 semester began in the campus and the students completed the first phase learning and working in the studio and in the maker lab. However, beginning from the second phase, the students received the program online. The rates dropped slightly: 3 out of 11 students succeeded AC2 and AC3, and 1 student managed to achieve AC4. Yet 4 students provided $\mathrm{AC} 1$ in their project, which can be related to the first phase of the program. Still, 1 student accomplished all the criteria in their project. The fully online semester, Fall 2020 , the decrease in the numbers of students in each criteria is evident: out of 18 students, 8 succeeded in AC1, 2 in AC2, 4 in AC3, and 3 in AC4. Only 2 students out of 18 covered the whole four criteria.

Beginning from the first phase until the end of the project, a thorough understanding of the brand identity and its embodied reflection to the space were under scrutiny. Accordingly, a proposal of interactive experience -whether it be supported by technological or analogous means- was expected to enhance the spatial experience. In the end, the overall project should have stemmed from a holistic approach towards design thinking and problem solving, including interactive experience and spatial integration. The fundamental alteration in the application of the program was the change of the physicality of the studio and the omission of the maker lab facilities. Thus, the student works and the field notes were evaluated from this perspective.

After the pilot study in Fall 2018, the following two semesters on campus reveal the increasing embodied experience in the student projects. Although reflection of brand identity to the space and the interactive experience increased in Spring 2019, this trend seems to decrease in the following three semesters. The first three semesters indicate that the collaboration with the maker lab has increased the use of technological and/or analogous tools in order to enhance the interactive experience. On the other hand, the expected holistic approach shows no apparent divergence in the meantime whereas it dramatically drops down in the online studio. Between face-to-face and online studio practices, the most apparent difference is the use of technological and/or analogous tools. The decrease of this criterion can be easily attributed to the lack of physical interaction among the students and the maker lab environment (Hynes and Hynes 2018). Consequently, the decline in the holistic approach can also be tied to this fact. Because, every means the maker lab provided the students continued in all the semesters except for the lab space itself, including the model making and digital prototyping tools.

It is not easy to draw conclusions on the comparison of the embodied experience and brand identity criteria between face-to-face and online studio experience, since it may suggest a differentiation on student basis. The grades of the students are also not directly related to their fulfilment of these four criteria. This may be both due to the inclination of the students to focus on the aspects that interest them the most and/or the motivation they pursue throughout the semester. As a limitation, it is worth mentioning that the effects of the pandemic on the motivation of the students and the first-time experience of online education both by the students and the instructors are discarded in the study. However, it would not be bold to say that for both cases executing a holistic approach including space, atmosphere, identity, and interactive customer experience (Pallasmaa, 2014) remained challenging. Yet, the critical analysis conducted in this study still maintains a promising attitude towards the role of the physical space which led to a direct interaction among the students and the instructors.

\section{Conclusion}

The implemented studio program both in faceto-face and online studio sought the extended means of the spatial experience in terms of the evolving modes of representation and use of technology which eventually would facilitate a transdisciplinary attitude towards retail interiors. As for the sake of the interior design 


\section{Journal of \\ Design Studio}

v:3 n:1 July 2021

studio, during the studio critiques the students were repeatedly reminded of the question of experiential spatial design and the necessity to support it with technological means. Accordingly, the projects would come out with a certain sense of integrating a holistic spatial solution towards the experience and technology with regards to the fundamental and sensory elements of interiors such as light, sound, color, material, texture, etc... As the literature suggests, it is crucial to adapt to the transforming retail experience, in which the interior designer can play a significant role in terms of communicating with the user, the brand, and the product. Yet, the experience of face-to-face and online interior design studio underlined the necessity of exploring the limitations of the physical space and the means of interaction. This study initially aimed to extend the limits of the interior design studio space and eventually experienced the online studio environment. Although the immediate actions were taken to adapt to the online studio, this first experiential and exploratory study shows us that the physical interaction has still a fundamental role in the interior design studio. The counterpart of the physical interaction in online education needs more investigation. Further studies and applications of design studio practices can alter the future of not only the retail store design but also the interior design studio education.

\section{References:}

Akin, O., (2002). Case-based instruction strategies in architecture. Design Studies, 23, 407-431.https://doi.org/10.1016/s0142694x(01)00046-1

Bagdare, S., Rajnish J., (2013). Measuring Retail Customer Experience. International Journal of Retail and Distribution Management, 41 (10), 790-804.

https://doi.org/10.1108/IJRDM-08-2012-0084.

Brakus, J. J., Schmitt B., Zarantonello, L., (2009). Brand Experience: What Is It? How Is It Measured? Does It Affect Loyalty?., Journal of Marketing, 73 (3), 52-68.

https://doi.org/10.1509/jmkg.73.3.52.
Cachero-Martínez, S., Vázquez-Casielles, R., (2017). Living Positive Experiences in Store: How It Influences Shopping Experience Value and Satisfaction?, Journal of Business Economics and Management, 18 (3), 537-53. https://doi.org/10.3846/16111699.2017.129231 1.

Ceylanl1, Z. \& Aktaş Yanaş, E., (2019). İç Mimarlık Tasarım Stüdyosunda Etkileşimli Mekân ve Deneyimsel Mağaza Tasarımı (Interactive space and experiential retail design in the interior architecture design studio). Türkiye'deki İç Mimarlık Eğitiminin Tarihi, Gelişimi ve Geleceği Ulusal Sempozyumu 1921 Aralık 2019, İTÜ Mimarlık Fakültesi, Taşkışla. (paper presentation)

Ciolfi, L., (2004). Understanding Spaces as Places: Extending Interaction Design Paradigms. Cognition, Technology \& Work 6 (1), 37-40. https://doi.org/10.1007/s10111003-0139-6.

Fleischmann, K., (2019). From studio practice to online design education: Can we teach design online? Canadian Journal of Learning and Technology, 45 (1), 1-18.

Forest, C. R.; Moore, R. A.; Jariwala, A. S.; Burks Fasse, B.; Linsey, J.; Newstetter, W.; Ngo, P. \& Quintero, C., (2014). The Invention Studio: A University Maker Space and Culture. Advances in Engineering Education, 4 (2), 132.

Helmefalk, M., (2019). Browsing Behaviour as a Mediator: The Impact of Multi-Sensory Cues on Purchasing, Journal of Consumer Marketing, 36 (2), 253-63. https://doi.org/10.1108/JCM10-2017-2392

Hynes, M. M. \& Hynes, W. J., (2018). If you build it, will they come? Student preferences for Makerspace environments in higher education. International Journal of Technology and Design Education, 28(3), 867-883. https://doi.org/10.1007/s10798-017-9412-5 


\section{Journal of \\ Design Studio}

v:3 n:1 July 2021

Hornecker, E., (2011). The Role of Physicality in Tangible and Embodied Interactions. Interactions, 18 (2), 19-23.

https://doi.org/10.1145/1925820.1925826

Imrie, R., (2003). Architects' Conceptions of the Human Body. Environment and Planning D: Society and Space, 21 (1), 47-65. https://doi.org/10.1068/d271t

Ioannou, O., (2018). Opening up design studio education using blended and networked formats. International Journal of Educational Technology in Higher Education, 15: 47. https://doi.org/10.1186/s41239-018-0129-7

Masdeu, M. \& Fuses, J., (2017). Reconceptualizing The Design Studio in Architectural Education: Distance Learning and Blended Learning as Transformation Factors. Archnet-IJAR: International Journal of Architectural Research, 11(2), 6-23. https://doi.org/10.26687/archnetijar.v11i2.1156

Mallgrave, H. F., (2010). The Architect's Brain: Neuroscience, Creativity, and Architecture, John Wiley \& Sons, Ltd., Publication, ISBN: 978-1-405-19585-0

Oxman, R., (1990) Prior knowledge in design: a dynamic knowledge-based model of design and creativity. Design Studies, 11 (1), 17-2. https://doi.org/10.1016/0142-694x(90)90011-z

Oxman, R., (2004). Think-maps: teaching design thinking in design education. Design Studies, 25, 63-91.

https://doi.org/10.1016/s0142-694x(03)00033-4

Pallasmaa, J., (2014). Space, Place, and Atmosphere: Peripheral Perception in Existential Experience. In C. Borch (Ed.), Architectural Atmospheres (pp. 18-41). Berlin, Boston: Birkhäuser.

https://doi.org/10.1515/9783038211785.18

Schmitt, B., (1999). Experiential Marketing. Journal of Marketing Management, 15 (1-3), 53-67.

https://doi.org/10.1362/026725799784870496.
Schmitt, B., (2003). Customer experience management: A revolutionary approach to connecting with your customer. New York, NY: John Wiley \& Sons.

Schmitt, B., (2010). Experience Marketing: Concepts, Frameworks and Consumer Insights. Foundations and Trends in Marketing, 5(2), 55112. https://doi.org/10.1561/1700000027

Scupelli, P.; Candy, S. \& Brooks, J., (2019). Teaching Futures: Trade-offs Between Flipped Classroom and Design Studio Course Pedagogies. International Association of Societies of Design Research Conference 2019 Proceedings.

Servais, E., Leroi-Werelds S., Katelijn Q. \& Jan V., (2018). "Conceptualizing The Value Of Physical Retailers: Comparing Marketing And Retail Design Perspectives". Paper presented at the 4th International Colloquium on Design, Branding and Marketing, Hasselt University, Belgium.

Quartier, K., Stephanie C., Jan V., (2019). A Holistic Competence Framework for (Future) Retail Design and Retail Design Education, Journal of Retailing and Consumer Services, https://doi.org/10.1016/j.jretconser.2019.101914.

Verhoef, P. C., Katherine N. L., Parasuraman, A., Roggeveen A., Tsiros M., Schlesinger, L.A., (2009). Customer Experience Creation: Determinants, Dynamics and Management Strategies. Journal of Retailing 85 (1), 31-41. https://doi.org/10.1016/j.jretai.2008.11.001

Vyas, D., van der Veer, G. \& Nijholt, A., (2013). Creative practices in the design studio culture: collaboration and communication. Cognition, Technology \& Work, 15, 415-443. https://doi.org/10.1007/s10111-012-0232-9

Yakhlef, A., (2015). Customer Experience within Retail Environments: An Embodied, Spatial Approach. Marketing Theory, 15 (4), 545-64.

https://doi.org/10.1177/1470593115569016. 